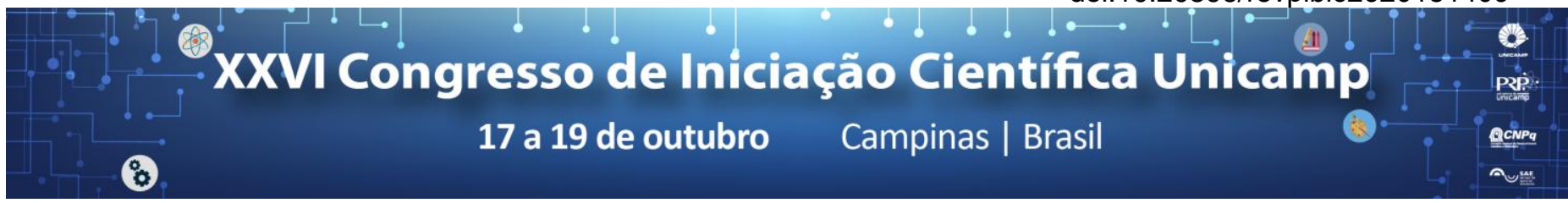

\title{
Experimento com Tubos Flexíveis para Supressão da Vibração Mecânica em Dutos Submarinos na Produção Marítima de Petróleo e Gás
}

\section{Matheus A. Vitorino da Silva*, Vinicius M. Ferraz*, Prof. Dr. Celso K. Morooka (Orientador); Leonardo P. A. Sales (Monitor); Caio C. O. Trigo (Colaborador Técnico)}

\section{Resumo}

Em certas regiões do solo marinho o riser pode ficar suspenso em vão livre, oscilando por conta das correntes marítimas. O uso de amortecedores pode atenuar a vibração excessiva, evitando assim um rompimento prematuro e consequentes desastres ambientais, acidentes e prejuízos. Portanto, o objetivo é testar se um amortecedor sintonizado pode atenuar tais vibrações. Para isso, analisou-se o comportamento de um modelo de riser para diversas frequências de oscilação forçada, avaliando a performance do amortecedor.

Palavras-chave: Engenharia de Petróleo, Risers, Sistemas Marítimos

\section{Introdução}

O riser, uma tubulação de aço que transporta fluidos do poço no fundo do mar à plataforma, deve vibrar pouco a fim de evitar seu rompimento. Por isso, testamos um amortecedor de risers para atenuar vibrações causadas por correntes marítimas.

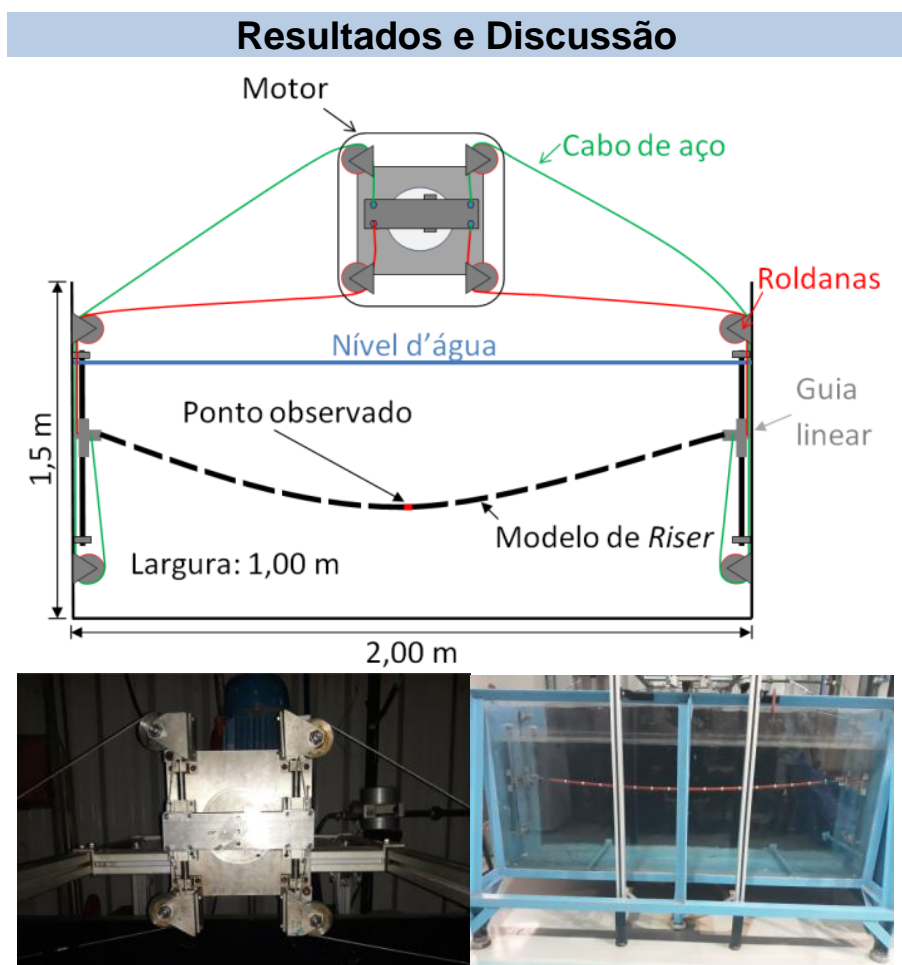

Figura 1. Esboço e aparato experimental (motor,tanque).

- Modelo de riser de borracha em escala reduzida de com diâmetro $D=19$ mm em vão livre.

- Oscilação forçada com amplitude $A=20 \mathrm{~mm}$, simulando correntes marítimas.

- Análise do intervalo de 0,25 a 1,80 Hz variando em 0,05 $\mathrm{Hz}$, com e sem o PTMD, configurado para amortecer a região entre 1,50 a 1,65 Hz.

- Registro em vídeos de 1 minuto do movimento vertical.

- Processamento de vídeo no Video Editor Pad e LabView, observando o ponto intermediário.
Na Figura 2, observa-se uma redução da amplitude de até $30 \%$ no intervalo indicado.

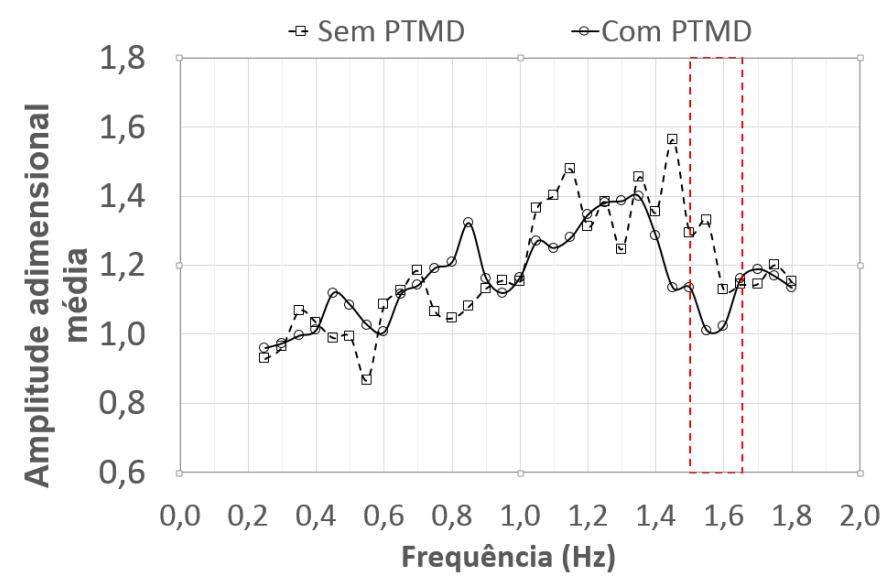

Figura 2. Amplitude adimensional média sem e com o

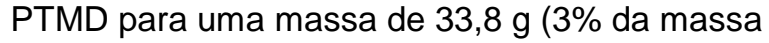
do sistema) e uma rigidez da mola de $3,28 \mathrm{~N} / \mathrm{m}$.

A Figura 3 mostra a redução de amplitude com e sem o PTMD na frequência $F=1,50 \mathrm{~Hz}$.

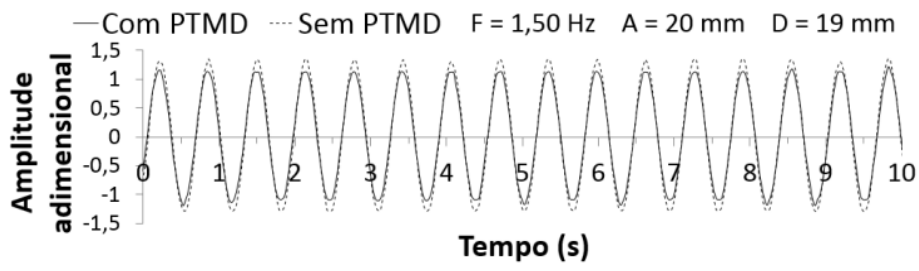

Figura 3. Série temporal da amplitude adimensional sem e com o PTMD para a frequência $F=1,50 \mathrm{~Hz}$.

\section{Conclusões}

O estudo permitiu avaliar a amplitude do movimento para diversas frequências. $\mathrm{O}$ sistema de amortecimento reduziu a oscilação para determinadas faixas de frequência. Análises aprofundadas serão necessárias para entender a interferência nas demais frequências.

\section{Agradecimentos}

Agradecemos a CNPq e a Pró-Reitoria de Pesquisa da Unicamp. 